\title{
$\underline{\text { A Street intercept strategy to research police corruption in Afghanistan }}$
}

\section{ABSTRACT}

Conducting research in an armed conflict setting can be a daunting task when faced with security, logistical and recruitment challenges. Moreover, when working with local agents for translation purposes there are additional problems with the veracity and accuracy of the research. However, there are various strategies to mitigate these problems that include a street intercept strategy and training interpreters. This article provides a methodological insight into a study on police corruption in the Afghan police force. Recruitment of Afghan police officers was built on a street intercept strategy and the interpreters utilised were trained and tested on language proficiency in English. The local company also specialised in logistics and security awareness that proved useful when relocating from Kabul to neighbouring provinces due to insecurity. This strategy can be considered by researchers when faced with security, access and logistical issues in volatile conflict-settings.

Keywords: Afghan police; street intercept; translation services; sampling; security challenges

\section{Introduction}

The article provides the position of research on Afghan police corruption. In an armed-conflict setting, the rationale of methods and modes of analysis chosen and the decisions made are based on security, logistics and ethics. The initial section of this article focuses on a literature review which shapes the research framework in order to answer the research question. The main section reveals the rationalisation of choices made that influenced the methods and sampling techniques undertaken in an extremely volatile environment during two phases of field research. This included a survey conducted in 2012 with 100 Afghan Uniform Police (AUP), mostly noncommissioned officers (NCOs) and low-ranked officers. Subsequently, 50 structured interviews 
with patrolmen, sergeants and lieutenants followed in 2016. It must be noted that the purpose of this article is to provide a methodology for identifying and approaching low ranking police officers in a post-conflict environment to survey or interview. The article demonstrates how the literature review has generated the research framework/research question which informs the methodology. Therefore, this article does not present findings or discussion sections on the data collected.

\section{Literature review}

Afghanistan is one of the most corrupt countries in the world. According to the Global Corruption Index measured by Transparency International (2016), Afghanistan is the second most corrupt country in the world which ranks after tied firsts Somalia and North Korea. Afghanistan is still undergoing an armed conflict and the police force is highly perceived as corrupt which has been exploited by the Taliban (Singh 2015, 239-241). The Taliban have gained support by defaming the Afghan police force with their 2006 code of conduct to act as an alternative means of security for many farmers and citizens residing in rural areas (Singh 2014, $622,627)$. The Taliban have gained some support in southern areas of the state by portraying themselves as an alternative to fight the corrupt administration and to put an end to police corruption (Sands, 2007; Pyman et al., 2012: 33-34). As a result, the Taliban have remobilised since the end of 2005-2006 which has caused further insecurity and fighting with the Afghan police force.

Hence, police corruption in Afghanistan has seriously hindered the legitimacy of the police force. The poor pay a higher slice of their household incomes on bribes regularly extorted from the low-paid police for economic survival (Singh 2016, 46). To explain this economic driver of corruption, the lower ranks of the Afghan police force remain low paid even after the late 2005 pay and rank reform structure (Wilder 2007, 39). The reform increased the number of patrolmen 
from 36,600 to 45,880 but the wages only increased from USD $\$ 25-\$ 70$ per month (Wilder $2007,39)$. This has been increased to $\$ 120$ but it remains too low to cater for living costs (Cann et al. 2010, 17).

Political drivers of corruption can also be stated. Many positions within the police force are based on patronage and ethnicity rather than meritocracy and the Interior Ministry arguably sells police chief posts, usually in high drug cultivating areas, to the highest bidders (Giustozzi and Isaqzadeh 2013, 89). Weak vetting with the Afghan police can lead to patronage practices because those that fail entry examinations include individuals who have committed human rights abuses (Singh 2015, 245). To provide one example, 14 police chiefs and 86 generals - some of whom have been engaged in previous human rights violations - were hired by former President Hamid Karzai despite failing their entry examinations (Wilder 2007, 40-41). This is a consequence of state capture. Additional consequences of state capture can be brought to attention. For instance, when ministers are engaged in corruption and drug trafficking, they are transferred to another ministry rather than being disbanded (Singh 2016, 61). For instance, exMinister of Interior, Zarar Ahmad Moqbel, was disbanded from his post in October 2008 due to US and British allegations of ineptitude, selling jobs and appointing predacious police chiefs that frequently conspired with drug smugglers but he was paradoxically voted back as chief of counter narcotics (Walling 2015). It can be argued that the Afghan government has exposed a lack of political will to challenge the drug trade and corruption. Those that retain powerful political positions in office override accountability measures. This explains how these political factors result in patronage and drug-related corruption.

In relation to the socio-cultural factors and cultural drivers of corruption, two points can be brought to attention. First, Azami (2009) argues that Afghan citizens regularly pay bribes to speed-up transactions and public services that are culturally accepted. Cultural explanations of corruption in the West are not compatible with Afghanistan because it is not imbued in the same 
symbolic explanations of the West. Second, irregular militias had pride and worked for a mandate during the Mujahidin regime, but this has been lost because there is now no sense of mission within the current Afghan police force (Singh 2015, 247). This point on police culture reveals that there is no noble cause to fight for. In other words, there is no sense of mission focusing on us versus them for the community, as Reiner $(1992,111)$ argues. The police lack pride to protect Afghans from security threats. With no noble cause, there is little emotional investment in their job.

These are some of the economic, political and cultural drivers of corruption which inform the methodology, namely the survey and structured interviews that investigate these drivers.

\section{Research framework}

This research uses thematic analysis within a framework of constructivism to theorise a relationship with the underlying themes and semantic. Braun and Clarke (2006) convincingly argue that themes can be generated by a researcher's assumptions to inform a research question but by keeping an open mind to any new potential findings beyond the themes when analysing the data. Based on the literature review, the researcher's assumptions are based on political, economic and cultural drivers of corruption within the Afghan police force. Taking these assumptions into consideration, the research question is; 'To what extent do political, economic, and cultural factors explain police corruption in post-conflict Afghanistan?' Considering this, the structural conditions (political drivers), economic coping strategy concerning low pay (economic drivers) and socio-cultural factors on what corruption covers (cultural factors) are the underlying themes that will be overlapped with the semantic. The semantic is police corruption in postconflict Afghanistan. Therefore, the underlying themes (political, economic and cultural drivers of corruption) explain Afghan police corruption (the semantic). 
The linked themes and the semantic will examine Afghan police corruption in order to work towards answering the research question on explaining police corruption in post-conflict Afghanistan. A post-conflict situation can include: a formal cessation of hostilities (usually with the signing of a peace agreement between all warring parties); disarmed, demobilised and reintegrated armed forces, rebels and irregular militias; the repatriation of refugees; and some degree of economic recovery (Brown et al. 2011,4). One could argue that Afghanistan has not fulfilled all of these features to classify it as a post-conflict environment because, in a brief response to the initial criterion, the late 2001 Bonn Agreement did not include the Taliban and hostilities have not ceased. However, the literature cites Afghanistan as a post-conflict setting and reference to this status will be made throughout this article because it is recommended by the researcher that research is not undertaken in states undergoing armed conflicts.

The first category of this conceptual framework is the political drivers that involve the structural causes of corruption, patronage and nepotism, state capture and ethnic favouritism. Clientelism is the exchange of material benefits which is also linked to nepotism, ethnic and tribal favouritism (Médard 1998, 308). Social life is penetrated to serve social groups that are usually affluent and hold some form of authority, status or prestige. State capture occurs when state regulations, policy decisions and laws become captive to the power of enterprises or groups in either or both the public or private sectors to the impairment of societal interests and accountability suffers significantly as a repercussion (Gressani and Mitra 2002, 9).

The second is the economic drivers of corruption which will cover the notion of corruption occurring as a means of economic necessity (namely due to low wages) that is linked to relative poverty and opportunity to engage in corruption due to the payoffs outweighing sanctions (Singh $2014,624,629,638)$. As part of the economic causes of corruption, low pay and anti-corruption strategies such as pay reform was studied. 
The third is the cultural drivers that concern the police as an organisation and occupation, police culture, the nature of police work, discretion and the culture of the international trainers that dictate methods of police reform. In the police context, an officer may overly exercise authority to extract a confession for the unit's gain (Cockcroft 2013, 121) as opposed to individual benefit.

\section{Research methods in the context of Afghanistan, 2012 and 2016}

After a discussion on the theoretical assumptions of the researcher in relation to the research framework, the remainder of this article discusses the research conducted in Afghanistan during two phases of field visits: January-March 2012 and April-May 2016. This section dissects the rationalisation of choices made in relation to the research methods adopted. It also covers changes in the research strategy, due to security and ethics committee recommendations, and street-intercept recruitment strategy.

\section{Survey in Kabul and 14 other provinces, January-March 2012}

This part introduces the purpose of the survey, including what they entailed in general. Predominantly, this section discusses the justification of choices made, including the security problems faced, and sampling with the lower levels of the Afghan police force during JanuaryMarch 2012. This commences with the objectives of conducting the survey and rationalisation of working with a logistics company for translation, logistical and security purposes. Subsequently, the strategy to relocate to other provinces due to security challenges faced in the field is covered. The penultimate section addresses the potential pitfalls of the survey, namely the presence of the researcher despite the survey being conducted in a different language unknown to the researcher. This is followed by generalisability and sampling issues that the survey faced which is largely due to the small sample size and difficulty to test for statistical significance in a variety of 
Afghan provinces.

\section{The purpose of the survey}

The reason why the lower ranks of the AUP were targeted was that there are no empirical studies conducted with them despite them making up the majority of the Afghan police force that consists of 169,000 . In particular, responses from senior levels would possibly differ when investigating pay levels of lower ranks and the links to petty corruption for economic survival. According to Bayley and Perito (2011), research on Afghan police corruption often consists of interviewing senior officers or international actors rather than street-level AUP. The survey data provides insight into some latent problems faced by lower-ranked police officers.

Table 1. Chart of hierarchy

\begin{tabular}{|c|c|}
\hline Non-commissioned & Officer ranking \\
\hline NCO Rank & Officer Rank \\
\hline Sergeant & Lieutenant general \\
\hline First Sergeant & Major general \\
\hline Second Sergeant & Brigadier general \\
\hline Third Sergeant & Colonel \\
\hline Patrolman & Lieutenant colonel \\
\hline First Patrolman & Major \\
\hline Second Patrolman & Captain \\
\hline Third Patrolman & First lieutenant \\
\hline Soldier & Second lieutenant \\
\hline
\end{tabular}

The chart of hierarchy provides the ranks for non-commissioned and officers within the Afghan police force. The ranks at the top are highest within their category.

A survey conducted with 100 patrolmen and some sergeants and first and second lieutenants commenced during January-March 2012. Police contacts were established by the researcher and 
subsequently a survey was designed for local researchers to conduct with the researcher's presence initially within the jurisdiction of Kabul's Ministry of Interior Affairs (MoIA). Permission was requested from police commanders or seniors to conduct research with patrolmen, sergeants and lieutenants under their jurisdictional territory. Once permission was obtained, a street intercept strategy was endorsed. This method entails the selection of research participants. Participants are randomly or non-selectively recruited direct from the street level to undertake a short-interview, survey, questionnaire or poll (Stacks 2011, 234). Street intercepts can be used as a social marketing strategy consisting of short and fast interviews that proceed with some qualifying screening questions to filter the eligibility of the respondents. This is followed by permission to complete a survey-based questionnaire usually in exchange for a small incentive; although no inducements were offered in this research. The street intercept method can be designed to access certain people on the street whilst performing their job-related tasks in which the interviewer screens participants to refuse non-qualifying persons (Miller et al. 1997, $655)$.

In relation to this research, random police officers were approached by the researcher and a private translation firm (because the researcher does not speak, or does not fully understand Dari) whilst they were working to answer a screening question on their current rank for the filtering process. If the police officers were a patrolman, sergeant or lieutenant, then the researcher, with the assistance of the translators, discussed the research objectives and permission to participate in the 10-minute survey. The private translation firm had English, Dari and Pashto capabilities, access and safe logistical facilities to Kabul's MoIA and Nangarhar. The firm also exercised discretion. All the responses were anonymised to job titles such as patrolman, sergeant or lieutenant within a province rather than stating names or the exact location of zones and/or districts. 
The survey questionnaires were short as advised from Afghan Post-war Reconstruction and Development Unit (PRDU) alumni - that were also ministerial and non-governmental organisation (NGO) workers - and police seniors due to security concerns and time constraints. This was a strategic decision to enable quick and effective responses in a hostile environment. The police institution was undergoing security threats in early 2012 in Kabul (Walsh and Popalzai 2012) which is why a quick and easy survey was prescribed. The MoIA was on red alert meaning that the street police were extremely busy. The survey was translated from English to Dari from a highly experienced survey-based researcher for the National Directorate of Security. This researcher also checked the reasonableness of answering the set questions within a 10-minute timeframe.

The private translation firm completed the survey response forms. The forms were immediately handed to the researcher and were stored by the researcher for analysis. The private translation firm did not attain any of the written responses. This was to protect them and comply with ethical conduct. Silverman $(2006,110)$ highlights that structured interviews require the researcher to be neutral without prompting the research participants' answers; no improvisation should occur such as rewording the questions and the research team require training to make sure that the interviews are consistent. The private translation firm were trained in this capacity and these instructions were briefed in order to ensure that the survey remained fixed and within a rigid format to avoid influencing answers. Furthermore, the researcher provided training in conducting surveys, controlling research biases and complying with ethics: namely informed consent, confidentiality and beneficence in accordance with the British Society of Criminology (BSC) (2015). The utility of the methodology can possibly be applied in other post-conflict settings when seeking translations, logistics and security. Therefore, the researcher and private translation firm remained neutral and impersonal.

All the 100 research participants, mostly patrolmen and some sergeants and first and second 
lieutenants, were asked the same standardised questions in the same sequence. The survey questionnaires consisted of set questions with certain responses but included other - please specify at times and allowed the research participants an opportunity to respond to a few openended questions. The set questions in the survey focused on junior police officers' experiences of patronage and corruption, the cost of living, location of their present post, pay, and rank reform. This also covered issues concerning the number of family members per household, the type of accommodation, the number of breadwinners per household, selection criteria (how they were recruited) and whether the police participant worked in a local or distant province. Moreover, their perceptions on corruption, patronage and anti-corruption within the entirety of the Afghan police institution were investigated. Therefore, some of these questions asked in the survey were based on demographics, salary and expenses.

An analysis had been utilised to focus on the economic and political drivers of corruption. The cultural drivers will be explored later in the structured interviews. The survey data was analysed quantitatively. Initially, the Statistical Package for the Social Sciences (SPSS) was utilised to provide a statistical analysis of the 100 survey responses. This enabled categorisations of salary levels, the number of family members and the participants' perceptions of the most prevalent forms of police corruption. This also enabled data on how the police participants were recruited and stationed. The focus was largely on the economic aspects of corruption. This was due to the literature indicating that a main driver of police corruption, particularly within the lower ranks, is that they are extremely low paid and unable to cater for their living costs and family expenses (Cann et al. 2010; Singh 2014).

The survey complied with informed consent, confidentiality and anonymity. The police participants were briefed of the research and the purpose of research outputs in academic journals. The police were also informed that their names would be anonymised and that they did not have to answer any of questions if they felt uncomfortable to do so. They signed a consent 
form. The police commander that held senior police authority was consulted prior to conducting the survey with patrolmen, sergeants and lieutenants within their jurisdiction. After permission was granted, random police officers were approached to screen the ranks of patrolmen, sergeants and lieutenants for potential participation. This street intercept strategy avoided any risks to all parties involved including effects on the participant's employment because they remained anonymous to their employers. The research also adhered with consent of the research participants within the permitted district zone and avoided influence from the police commander to provide certain answers.

\section{Relocation due to security constraints}

It was envisaged for the survey to be conducted in Kabul close to the MoIA but the security crisis in late February - March 2012 led to the researcher and private translation firm relocating to other provinces. This part covers the security challenges that resulted in relocation to conduct the majority of the survey.

The survey was initially conducted in centralised and urban Kabul nearby the Interior Ministry for the purpose of generalising the findings within one jurisdiction/policing area. Sixteen survey questionnaires were initially conducted in Kabul. However, the researcher and private translation firm made the decision to relocate to 14 other provinces to conduct the remainder of the survey due to the security crisis in the MoIA in Kabul. On 22 February 2012, North Atlantic Treaty Organisation (NATO) troops had burned copies of the Qur'an that had allegedly been used by Taliban detainees to communicate messages at Bagram's US Air Base library which initially caused 2,000 Afghan protestors throwing stones and petrol bombs outside the military gates (Marthone 2015, 150). This led to nationwide protests and approximately 4,000 people protested and flung stones at the Afghan police force nearby the Kabul-based MoIA (Kuz 2012). As a result, 30 Afghan civilians were killed and two highly ranked US army 
advisors were shot dead within an alleged secure area of the Afghan MoIA (Bowley 2012; Henderson 2012). NATO promptly removed hundreds of armed force trainers from Kabul's MoIA. In total, the protests amounted to at least 41 fatalities, 270 injuries and the Taliban claimed responsibility for killing four US military personnel (Marthone 2015, 150-151). In addition, numerous coordinated attacks commenced in Wazir Akbar Khan which targeted the MoIA and the US and UK embassies. Therefore, the private translation firm and the researcher decided that the survey was to be completed in the home provinces of the local firm. The firm had better logistics in their familiar home provinces. The logistics in Kabul was poor in early February - March 2012 due to the aforementioned security threats. The remainder of the survey questionnaires were conducted in near provinces but evaded southern Afghanistan due to poor security and inaccessibility (Chouvy 2010, 56).

The survey consisted of 100 questionnaires conducted with lower-ranked AUP with the assistance of the local firm due to their translation services, logistics and ability to relocate during security threats. The survey provided data on the principal matters of corruption in the Afghan police institution to complement the predominant issues of corruption and clientelism that impedes Afghan law enforcement (as cited in the literature review).

\section{Limitations of the survey}

There are two main problems with surveys such as questionnaires. First, the research participant may provide answers that the interviewer may wish to receive or to omit certain information from them (Bradburn 1983). Second, there may be concerns with the way questions are worded and thus the purpose of surveys and structured interviews is to reduce errors (Fontana and Frey 1994, 364).

It is debatable as to whether the presence of the researcher helped the process or hindered it. On one hand, the questions were strictly adhered to but on the other hand, the police participants 
may have felt uncomfortable with foreign presence and English language spoken between members of the private translation firm and the researcher. This may have been the case to either please or omit information from the researcher. Moreover, using interpreters provides an additional construct to validity when translating a question and answer which was, at least to an extent, mitigated with English and Dari language proficiency tests. When translators and translations are utilised in a study, an additional construct to the validity arises. In relation to this study, one can question the veracity of the translations from Dari and Pashto to English provided by the private translation firm during the survey in 2012 (and structured interviews in 2016). When analysing other research that has used proxies for translation services (interpreters), there are notable constraints to the validity of the research.

A study on student nurses' educational programmes conducted by Kapborga and Berterö (2002) revealed that when interviewing with an interpreter there are potential hazards to validity during the process. Ten female nurses were interviewed in Lithuania by a Swedish researcher (bilingual also knowing English) who utilised an interpreter to translate English to Lithuanian and vice versa for the interviewer to receive Lithuanian responses in English (Kapborga and Berterö 2002). The threats to the validity of the study arose during both translations from the initial question asked by the interviewer and the response of the interviewee because there was no assurance that the interpreter had translated verbatim rather than merely summarising and/or modifying the response. Kapborga and Berterö (2002, 55) conclude that this is why the interpreter must have research training in the field rather than just having linguistic competence.

Other research from Waddington (2001, 311-312) contends that researchers should acknowledge that when conducting quality assessment of text translations, there are translation errors made during the translation process. Using an interpreter in research results to challenges with an array of constructs which includes language proficiency and accuracy but in order to enrich construct validity the researcher can measure the oral and written language proficiency of 
the interpreters utilised (Hale and Napier 2013, 164). Capability with language is a latent construct that researchers need to try to minimise (Schmidt and Embretson 2003, 433).

In relation to this research, the questions for the questionnaires were checked by several Afghan governmental and NGO workers who were also PRDU alumni to decrease inaccuracies. All were fluent in Dari and English and had a high degree of field experience conducting surveys and interviews for numerous organisations. Proficiency tests based on the International English Language Testing System were conducted with the hired firm. This test measures English reading, writing, speaking and listening skills.

Other limitations of the research methods are based on accessibility and physical security of the researcher and translation firm involved in a volatile state. While the bulk of opinions and responses provided by the police survey respondents have had experiences of working and living in other Afghan provinces, Afghanistan contains 34 provinces. All provinces contain different practices, services, dispute resolutions and methods of law enforcement and crime control that may lead to different experiences and perceptions of corruption in such localities.

\section{Generalisability and sampling issues}

The data cannot be generalised to a larger population within an Afghan province or the state. Hence, the results of the survey are not generalisable. The survey has not undergone vigorous tests of statistical significance due to the small sample size. The survey was held in different provinces due to the security and logistical constraints during early 2012. Even if the same samples were designated from the same population, it cannot be presumed that the relationship and results would be identical or considerably dissimilar from the first if a second sample were adopted. The BSC $(2015,4$.iv) underlines that researchers can face difficulty when attempting to undertake cross-national or comparative research within different locations where different codes and practices commence. This is why this research does not aim to provide a cross-comparative 
analysis. Rather, the sampling of the survey was done so based on the security of the researcher and private translation firm and not strategically. No census can be grasped and the connection between the variables measured can arguably occur by random chance which is what tests for statistical significance try to avoid (Fisher 1925). Detecting a probability of a present relationship would provide an error especially with a small survey size in various geographic locations within one mountainous country. Despite this reporting of a negative finding, the method can give insight from a qualitative perspective and while not generalisable, deepens our knowledge on the drivers of corruption within a post-conflict setting. The qualitative advantages of this research are based on the perceptions of the main causes, practices and definitions of Afghan police corruption that are presented by the police participants. Rather than merely focusing on the statistics or testing for statistical significance, the survey serves the purpose to provide the meanings and activities of police corruption according to the perspectives of the lower ranks of the Afghan police force. Hence, the main advantage of this research is based on the qualitative (and new empirical) findings based on street-level daily activities as presented from the police participants.

At times, predominantly in volatile environments or if the research team has low financial and human capital, poor logistics and security, the research may adopt a small sample size. This is evident with this research. The alterations may be small and therefore the differences are insufficient to be statistically significant. It is impossible to provide any generalisation of the findings solely based on geographic locations. It is also not possible to assume that other parallel surveys conducted in the same areas would result in the same findings (Blaikie 2010, 192). The BSC $(2015,3 . i v)$ state that researchers have the responsibility to avoid overgeneralising limited data and need to be aware of over and underrepresenting certain groups. Sampling and testing for statistical significance are thus issues to this research due to the lack of security, logistics and access. The answer generated to respond to the research question will only partly reflect on the 
views provided in the survey. Despite the drawbacks of failing to generalise the findings, the survey is innovative as it is conducted with lower ranks of the Afghan police. Often, the opinions of higher ranked police personnel and/or international trainers are gathered from numerous studies with them revealing the problems that the lower ranks experience and the types of corruption they are involved in (Wilder 2007; Karp and Ponzio, 2007; Bayley and Perito, 2011, 12). The AUP's opinions on police corruption, clientelism and anti-corruption includes data obtained on their living situations, income and costs, and whether they thought that their salary was adequate to provide for living costs and familial expenses.

\section{Structured interviews, April-May 2016}

This part provides the rationale for conducting structured interviews with patrolmen, sergeants and lieutenants. It discusses the purpose of the structured interviews that incorporates some of the questions from the survey on the economic drivers of corruption and the data collection process. A brief overview of the intention for the same private translation firm utilised for the survey in 2012 to conduct the structured interviews without the presence of the researcher follows. This is due to their language capabilities, access, logistical facilities and knowledge of ethical considerations and the ability to blend in local society. These characteristics are fundamental for successful application of the street intercept strategy in a challenging environment. The final part discusses sampling strategies that were endorsed and the potential to generalise the data collected from the structured interviews.

\section{The purpose of the structured interviews}

The structured interviews in April-May 2016 were conducted in Kabul with 50 NCOs and lower ranked Afghan police officers. Each interview consisted of 20 minutes. Structured interviewing consists of predetermined questions with some rigid categories for the responses and there is 
only opportunity for variation in the occasional open-ended questions (Fontana and Frey 1994, 363). The questions for the structured interviews contained some of the same or similar standardised questions utilised in the previous survey conducted in 2012. These set and rigid questions covered the demographics of the junior police, perceptions on corruption, patronage and anti-corruption and the economic drivers of corruption. These questions were similar to the survey but included added questions on the cultural drivers of corruption. The same or similar questions contained in this structured interview were based on economic aspects of life, such as monthly salary, expenses and earners per household, and on recruitment, training and perceptions on corruption. The economic determinants of corruption intend to provide comparisons with the survey. Only comparisons are provided on the same questions asked on the economic aspects of corruption. However, the structured interviews also included the addition of some open-ended questions. These open-ended questions were based on police participants' perceptions of corruption, what the main forms of corruption entail in daily practices and cultural understandings of the Afghan police as an organisation, police work, police solidarity, relations with civil society and collective behaviours. Therefore, the survey was based on closed rigid responses and each had taken 10 minutes to complete but the structured interviews were more indepth and approximately lasted 20 minutes.

Based on the previous success of the survey conducted in 2012, a pilot study with the structured interviews did not commence. Moreover, as with the 2012 survey, the same street intercept method was utilised with the 2016 structured interviews by approaching random potential participants in zones permitted from superiors with initial screening questions on rank. If the police officers were patrolmen, sergeants or lieutenants then they qualified as potential research participants. With the street intercept strategy, there were no instances of the structured interviewees being fortified and/or influenced by the police commander to give particular responses during the structured interviews. Reiner (2010) has argued that if a police chief or 
chief constable authorises the presence of researchers, then this does not necessarily result in the police accepting such presence or full participation in the research but rather obstructive assistance is the outcome.

Consent was complied with the research participants within the permitted district zone. As recently stated, once permission was obtained from senior police officers random AUP officers were approached for participation if they qualified as a patrolman, sergeant or lieutenant. Prior to participation, the police commander, or other senior police authority, was consulted before conducting the structured interviews with the respondent within the senior's dominion. After the senior commander who permitted jurisdictional access to their NCOs and police officers, senior officers were provided with a consent form to sign. This was so that both the researcher and research participant had permission obtained from the senior police of authority within the district zone to conduct research within their jurisdiction with the participants to circumvent any risks to all parties involved.

The next phase of the recruitment process included explanations from the interviewer from the private translation firm based on the relevant participant briefing form with the qualifying persons: NCOs or lieutenants. Subsequently, the form was left with them and if the potential participant agreed to participate in the research then they signed a consent form. If they consented, then the research participants were anonymised so that their responses could not be traced by their police commander or any other party in order to mitigate what Reiner (2010) stresses on obstructive assistance. When having read the participant briefing form, if a participant wished to withdraw their questionnaire from the sample they could have their data removed. Each has a number (e.g. structured interview \#3) so their responses were and remain anonymised and could and can be identified by the researcher in the event of requested removal. The police participants were informed of the research and the purpose of the research for academic publications, conferences and potential policy recommendations. The AUP was also 
informed that their names would be anonymised and that they did not have to answer any of questions if they felt uncomfortable to do so. Therefore, similar to the survey, these structured interviews adhered to informed consent, confidentiality and anonymity.

Once the data was analysed, a summary of the results was offered to the police commanders/seniors via the private translation firm - the same ones that granted permission to approach NCOs and lowly ranked officers in their jurisdictional zones - for them to disseminate amongst these ranks in their zone. The police commanders are unable to identify any responses because all data has been anonymised and thus participation has not affected the employment of the participants or added to any further security risks.

Despite these controls, it is important to note that similar to the survey, it is debatable as to whether the research participants felt at ease to enclose information on sensitive issues of police corruption. The work of Fleming $(2010,144)$ has noted that the police are historically a closed institution; the police shield their secrets; and resent intrusion. Hence, there is a clash with academia seeking to explore and criticise versus police closed-values.

\section{Changes to the research strategy}

It was initially envisioned for the researcher to hire the same private translation firm that the researcher worked with during the survey conducted to provide translations, logistics and access for the structured interviews. However, the relevant ethics committee rightly recommended that the researcher should not enter the field on the grounds of security and insurance issues. The Insurance and Risk Officer stated that local agents could conduct the survey.

In April 2016, the researcher contacted the private translation firm and they indicated that they were ready to conduct the structured interviews without the presence of the researcher. The firm is familiar with the research. They have provided translation services for the survey conducted in 2012 with the presence of the researcher. It is also hard to state with certainty as to 
whether the translation firm fully adhered with the set questions because the researcher does not speak Dari. It may be more beneficial to have the translation firm conduct the structured interviews without the presence of the researcher to avoid the risk of the police officers feeling uncomfortable when answering questions on corruption. The researcher did not have any influence with the research participants but was in the unlikely event reachable from telephone and email for any queries or concerns made from the private translation firm.

The dynamics concern the effects on class, regional accents, dress and wealth and thus the researcher did not interact directly with the police officers. The researcher allowed the local agents to conduct the structured interviews due to their local knowledge of the Dari dialects in certain areas in order to mitigate the aforementioned dynamics. The translation firm conducted the structured interviews where the anonymised participant could not be identified by members of the public. The structured interviews were therefore conducted by locals who knew the area and had access to the AUP. The research participants had undertaken participation, in the aftermath of granting permission from the authorising territorial commander or senior, whilst patrolling within their jurisdiction during working hours with the private translation firm. The firm dressed like locals and spoke the same native language to avoid any potential suspicion. Therefore, participation in the structured interviews was undertaken whilst the participants were remunerated by their employer meaning that in the event of any security liability they would be covered under their employer's insurance. All participants were covered under public liability insurance in the event of negligence. A dressed local speaking with a patrolman, sergeant or lieutenant on the street within their working hours and jurisdiction for 20 minutes did not impede on security issues or add further risks.

The structured interview questions have been translated from English to Dari by the private translation firm which has then been further translated by Afghan PRDU alumni to enhance the accuracy of translations. The firm read the structured interview questions in Dari to the research 
participants and recorded the responses in English on the questionnaire response forms. This is so that the translation process did not take too much time in order to ensure that each structured interview could be completed in approximately 20 minutes. As with the survey in 2012, this was possible to achieve because the researcher did not require thorough and immediate verbal translations to provide follow on questions related to the responses as would be the case with semi-structured interviews. The translation firm stored the written recorded questionnaire response forms until 50 were completed. After two years, the questionnaire response forms have been destroyed in confidential waste by the researcher. The translation firm had been alerted to avoid sharing the response forms with any other party in order to comply with ethical standards and avoid any risks to themselves and the research participants.

It was initially envisaged to conduct 100 structured interviews but the figure of 50 had been finalised due to the additional time that was undertaken with the additional open-ended questions in comparison to the earlier survey. It was unlikely that the senior police within jurisdictions nearby to the MoIA in Kabul would permit research to exceed 20 minutes per respondent. One could argue that semi-structured interviews or even unstructured interviews would be more beneficial but these are generally more time consuming. Due to the researcher's experience with conducting a survey on the ground with Afghan patrolmen, sergeants and lieutenants, they are restricted to time when engaging in research as instructed by their senior colleagues.

\section{Security awareness}

Due to the post-conflict or ongoing-armed conflict situation in Afghanistan, security, logistics and access were concerns. The private translation firm assisted with such issues, which was evident with their services in the 2012. This included dealing with high insecurity in Kabul. The high hostility level in 2016 was a prime factor why caution was undertaken with the departmental decision for the researcher to enter the field. The research did not put the private 
translation firm in danger because they had strong logistics. If there were any high security alerts, then it was instructed by the researcher that the research would be put on hold. In such events, the translation firm relocated to Nangarhar - a nearby province that is familiar to the firm and is relatively safe - to conduct the remainder of the structured interviews.

\section{Sampling and generalisability}

Tests for statistical significance were once more issues with the research. Yet, the police participants were targeted in specific districts in Kabul and Nangarhar in order for purposive sampling to commence. Purposive sampling as a non-probability sample based on the study objectives of police corruption was conducted on the AUP and the parameters of the participants were the lower levels of the Afghan police. Purposive sampling consists of selective, judgemental or subjective sampling - usually desired groups, individuals and settings for the relevant research and/or case study - rather than random sampling that includes a diverse range of groups and/or individuals (Silverman 2006, 306-307). Purposive sampling therefore focuses on a group, setting, organisation or individuals with certain characteristics who would serve best to assist with the research (Silverman 2010, 141). In this case, it is patrolmen, sergeants and lieutenants within one or two Kabul and Nangarhar districts that consisted of the core of the structured interviews conducted. Yet, the districts have been anonymised to protect the respondents from being traced due to the sensitivity of the environment and subject.

It can also be argued that theoretical sampling applies to the structured interviews due to selected groups being studied based on the research question to test the theoretical propositions, explanations (Mason 1996, 93-94) or research framework in this case. In relation to this study, the lower levels of the Afghan police are the selected group to investigate the research question by exploring the political, economic and cultural drivers of corruption. With purposive and theoretical sampling, the researcher influences the theory, analysis and sampling undertakings 
(Mason 1996, 100). These methods of sampling can thus be utilised flexibly such as increasing the sample size or focusing on a small segment of the sample (Silverman 2006, 309-311). These sampling techniques were attempted with the structured interviews in April-May 2016 to enhance the generalisability of the research with the participants in specific police districts in Kabul and Nangarhar. Yet, the researcher is sceptical that a certain degree of representativeness will allow superficial inferences to an entire locality.

\section{Conclusion}

The methods in this research consisted of a survey and structured interviews with street-level Afghan police officers to investigate the theoretical assumptions of the researcher on the political, economic and cultural drivers of corruption within the police force. The literature review indicates that police corruption in Afghanistan has fuelled the Taliban insurgency that has aggravated insecurity within a protracted armed conflict (Singh 2014). The literature review has helped to generate the research framework and research question which subsequently informs the methodology. The survey questionnaires and structured interviews work together by investigating perceptions of the AUP on the causes and consequences of corruption in the Afghan police force. This provides more comprehension on the political, economic and cultural drivers of corruption (beyond the literature review) and an empirical contribution to the field. The methodology may not result in quantifiable data but the negative finding obtains qualitative data. The researcher has tried it and while useful (quantitatively) in some settings, it is not appropriate in a post-conflict environment. An opportunistic and purposive sampling strategy was adopted with this research because an appropriate sampling strategy is not possible within a hostile environment due to the security, logistical and language challenges. These challenges existed with this research which is why a private translation firm was hired to assist when interacting with the police participants in selected safe areas due to issues with security and 
logistics. Research in a post-conflict environment, or what Bush and Duggan $(2013,8)$ term as a violently divided society, needs to take the ethical, methodological, logistical and political (which includes security) factors into consideration. These four challenges make conducting research in post-conflict environments difficult, although not impossible. This is why access is difficult (logistical) and sacrifices to the research and sampling strategy (methodology) are considered to ensure that the researcher, local agents - or research assistants - and the research participants are safe with relocation options (political/security) and adhere with anonymity (ethical).

The recruitment strategy consisted of street intercepts which worked well when obtaining permission from senior officers/police commanders and the screening questions with potential participants. In January-March 2012 when an investigation on Afghan patrolmen, sergeants and first and second lieutenants was conducted during a period of high hostility levels, it resulted in the researcher adopting a short 10-minute survey with the use of translation services. Subsequently, the researcher and the private translation firm relocated to neighbouring provinces due to high insecurity caused from fighting between the Taliban and Afghan police within and nearby the MoIA. This was the safest and fastest way to collect data during this period. The same strategy was prescribed during the structured interviews in 2016 but without the physical presence of the researcher due to the recommendation made by the relevant research ethics committee. The private translation firm dealt with the majority of the queries. The firm had been trained by the researcher in 2012 on informed consent, confidentiality and beneficence. They had agreed to comply with the ethical guidelines provided by the BSC (2015) to ensure compliance with basic ethical conduct when conducting the structured interviews in 2016. The private translation firm were presented with English and Dari language proficiency tests to ensure that the veracity of the data collected is credible. The street-intercept recruitment strategy was adopted effectively and safely within a hostile environment for the survey and structured 
interviews. This strategy can be considered in other hostile environments, with the assistance and translations of local agents, when problems with logistics, access and security are faced by the researcher.

\section{Acknowledgements}

The author would like to thank the private translation firm for their expertise in security, logistics and assistance with accessing police units in predominantly Kabul and Nangarhar.

\section{References}

Azami, S. 2009. "The Need for Security Sector Reform in Afghanistan to Curb Corruption." Peace \& Conflict Monitor, November 4.

Bayley, D., and R.M. Perito. 2011. "Police Corruption: What Past Scandals Teach about Current Challenges." United States Institute of Peace Special Report 294, November.

Blaikie, N. 2010. Designing Social Research. 2nd ed. Cambridge: Polity Press.

Bowley, G. 2012. "Two American Soldiers Die in Shooting at Afghan Base." The New York Times, August 6.

Bradburn, N.M. 1983. "Response Effects." In Handbook of Survey Research, edited by P.H. Rossi, J.D. Wright and A.B. Anderson, 289-328. New York: Academic Press.

Braun, V. and V. Clarke. 2006. "Using Thematic Analysis in Psychology.” Qualitative Research in Psychology 3 (2): 77-101.

British Society of Criminology. 2015. Statement of Ethics for Researchers in the Field of Criminology. London: BSC Publications.

Brown, G., A. Langer and F. Stewart. 2011. "A Typology of Post-Conflict Environments." Centre for Research on Peace and Development Working Paper 1, September. 
Bush, K. and C. Duggan, 2013. "Evaluation in Conflict Zones: Methodological and Ethical Challenges. ” The Journal of Peacebuilding and Development 8 (2): 5-25.

Cann, J.P., C.S. Ploszaj and W.B. Simpkins. 2010. "Policing for Afghanistan Reform that Respects Tradition: Need for a Strategic Shift.” Institute for Defence Analyses Paper P-4604, May.

Chouvy P-A. 2010. Opium: Uncovering the Politics of the Poppy. London: I.B. Tauris.

Cockcroft, T.W. 2013. Police Culture: Themes and Concepts. London: Routledge.

Fisher, R.A. 1925. Statistical Methods for Research Workers. Edinburgh: Oliver and Boyd Publishers.

Fleming, J. 2010. "Learning to Work Together: Police and Academics." Policing: A Journal of Policy and Practice 4 (2): 139-145.

Fontana, A. and J.H. Frey, 1994. "Interviewing: The Art of Science." In The Handbook of Qualitative Research, edited by N.K. Denzin and Y.S. Lincoln, 361-376. Thousand Oaks, CA: Sage Publications.

Giustozzi, A. and M. Isaqzadeh. 2013. Policing Afghanistan: The Politics of the Lame Leviathan. London: Hurst and Company.

Gressani, D. and S. Mitra. 2002. "Structural Reforms in Southeastern Europe since the Kosovo Conflict." World Bank: Europe and Central Asia Poverty Reduction and Economic Management Series Technical Paper 526.

Hale, S. and J. Napier. 2013. Research Methods in Interpreting: A Practical Resource. London: Bloomsbury.

Henderson, B. 2012. "US Troops Burned 100 Copies of the Koran in Afghanistan." The Telegraph, August 27.

Kapborga, I. and C. Berterö. 2002. "Using an Interpreter in Qualitative Interviews: Does it Threaten Validity?" Nursing Inquiry 9 (1): 52-56. 
Karp, C. and R. Ponzio. 2007. "NATO, SSR and Afghanistan." In Intergovernmental Organisations and Security Sector Reform, edited by D.M. Law, 219-235. Zürich: LIT Verlag.

Kuz, M. 2012 “Afghanistan Suffers Deadliest Day of Protests.” Stars and Stripes, February 24. Marthone, W. 2015. Under Fire. Raleigh, NC: Lulu Press.

Mason, J. 1996. Qualitative Researching. London: Sage Publications.

Médard, J-F. 1998. “Afterword.” In Political Patronage in Contemporary Societies, edited by JL. Briquet and F. Sawicki, 307-316. Paris: University Presses of France.

Miller, K.W., L.B. Wilder, F.A. Stillman and D.M. Becker. 1997. "The Feasibility of a StreetIntercept Survey Method in an African-American Community." American Journal of Public Health 87 (4): 655-658.

Pyman, M., J. Cohen, M. Boardman, B. Webster and N. Seymour. 2012. Arresting Corruption in the Police: The Global Experience of Police Corruption Reform Efforts. London: Transparency International United Kingdom.

Reiner, R. 1992. The Politics of the Police. 2nd ed. Harvester: Wheatsheaf.

Reiner, R. 2010. The Politics of the Police. 4th ed. Oxford: Oxford University Press.

Sands, C. 2007. "Bring Back Taliban to End Police Corruption.” The Independent, May 10.

Schmidt, K.M. and S.E. Embretson. 2003. "Item Response Theory and Measuring Abilities.” In Handbook of Psychology: Volume 2 - Research Methods in Psychology, edited by J.A. Schinka and W.F. Velicer, 429-446. Hoboken, NJ: John Wiley and Sons, Inc.

Silverman, D. 2006 Interpreting Qualitative Data: Methods for Analysing Talk, Text and Interaction. 3rd ed. London: Sage Publications.

Silverman, D. 2010 Doing Qualitative Research: A Practical Handbook. 4th ed. Los Angeles, CA: Sage Publications. 
Singh, D., 2014. "Corruption and Clientelism in the Lower Levels of the Afghan Police." Conflict, Security \& Development 14 (5): 621-650.

Singh, D., 2015. "Explaining Varieties of Corruption in the Afghan Justice Sector." Journal of Intervention and Statebuilding 9 (2): 231-255.

Singh, D. 2016. "Anti-Corruption Strategies in Afghanistan: An Alternative Approach.” Journal of Developing Societies 32 (1): 44-72.

Stacks, D.W. 2011 Primer of Public Relations Research. 2nd ed. New York: The Guilford Press.

Transparency International, 2016. Corruption Perceptions Index 2015: Corruption Still Rife but 2015 Saw Pockets of Hope, 27 January. Berlin: International Secretariat for Transparency International.

Waddington, C. 2001. "Different Methods of Evaluating Student Translations: The Question of Validity." Meta: Translators' Journal 46 (2): 311-325.

Walling, M.G. 2015. Enduring Freedom, Enduring Voices: US Operations in Afghanistan. Oxford: Osprey Publishing.

Walsh, N.P. and M. Popalzai. 2012. “4 Killed in Afghanistan Amid Outrage Over Qur'an Burning." Cable Network News, February 25.

Wilder, A. 2007. Cops or Robbers? The Struggle to Reform the Afghan National Police. Kabul: Afghanistan Research and Evaluation Unit. 